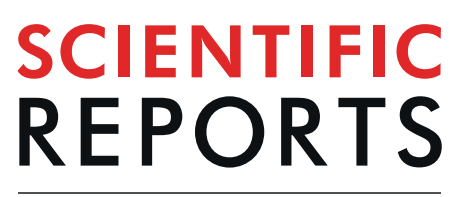

\title{
Comparing the rates of methane production in patients with and without appendectomy: results from a large-scale cohort
}

Will Takakura ${ }^{1}$, Sun Jung $\mathrm{Oh}^{1}$, Tahli Singer-Englar ${ }^{2}$, James Mirocha ${ }^{3}$, Gabriela Leite ${ }^{2}$, Adie Fridman $^{4}$, Mark Pimentel ${ }^{2}$, Ruchi Mathur ${ }^{2}$, Nipaporn Pichetshote ${ }^{2}$ \& Ali Rezaie ${ }^{2 *}$

There is no clear study identifying the microbiome of the appendix. However, in other diverticular conditions, such as diverticulosis, methanogens appear important. We investigated whether patients who had undergone appendectomies had decreased levels of exhaled methane $\left(\mathrm{CH}_{4}\right)$. Consecutive patients who underwent breath testing (BT) from November 2005 to October 2013 were deterministically linked to electronic health records. The numbers of patients with $\mathrm{CH}_{4} \geq 1$ $\mathrm{ppm}$ (detectable) and $\geq 3$ and $\geq 10 \mathrm{ppm}$ (excess) were compared between patients who did and did not undergo appendectomy using a multivariable model adjusted for age and sex. Of the 4977 included patients ( $48.0 \pm 18.4$ years, $30.1 \%$ male), $1303(26.2 \%)$ had $\mathrm{CH}_{4} \geq 10 \mathrm{ppm}$, and $193(3.9 \%)$ had undergone appendectomy. Appendectomy was associated with decreased odds of $\mathrm{CH}_{4} \geq 1, \geq 3$, and $\geq 10 \mathrm{ppm}(\mathrm{ORs}(95 \% \mathrm{Cl})=0.67(0.47-0.93), p=0.02 ; 0.65(0.46-0.92), p=0.01$; and $0.66(0.46-$ $0.93), p=0.02$, respectively). Additionally, the percentage of $\mathrm{CH}_{4}$ producers increased 4-fold from the first to ninth decade of life. This is the first study to report that appendectomy is associated with decreased exhaled $\mathrm{CH}_{4}$. The appendix may play an active physiologic role as a reservoir of methanogens.

The appendix is a narrow vermiform organ connected to the caecum. In humans, it can become inflamed and can be surgically removed without any overt consequences; therefore, it is often thought to be a vestigial organ. Some studies have cast doubt on this theory, arguing its potential role in immune function and maintenance of the gut microbiome. Its immunologic role is evidenced by histologic studies showing that the appendix houses large amounts of lymphoid tissues with both active T cells and B cells ${ }^{1}$. It is also a relatively rich source for IgA, and its activity seems to be maintained well into adulthood ${ }^{2}$. Moreover, the appendix contains a thick biofilm ${ }^{3}$, in which an abundance of microbes live $e^{4,5}$. The location and unique shape of the appendix makes it an ideal organ in which commensal organisms can be housed to repopulate the colon after the colonic gut microbiome has been modulated during diarrhoeal illnesses. However, to date, appendectomy has not been linked with an objective and clinically relevant microbial change.

Archaea are a unique group of microbes that share some features of bacteria (single circular chromosomes that lack introns with similar post-transcriptional modifications) and eukaryotes (use of histones in DNA packing and similar DNA replication, transcription, and translation mechanics) ${ }^{6}$. Most archaea in the human gut have a unique metabolic role in that they produce methane $\left(\mathrm{CH}_{4}\right)$ as the end-product of their metabolism ${ }^{7}$. Most reduce carbon dioxide in the presence of hydrogen $\left(\mathrm{H}_{2}\right)$ to produce $\mathrm{CH}_{4}{ }^{8}$. Two strict anaerobic strains of methanogens have been described in the human gut: Methanosphaera stadtmaniae ${ }^{9}$ and Methanobrevibacter smithii ${ }^{10}$. Methanogens have been associated and/or implicated in numerous human diseases, such as obesity, anorexia, constipation-predominant irritable bowel syndrome, periodontitis, and diverticulosis ${ }^{11}$.

In the clinical setting, breath testing (BT) is utilized to indirectly measure concentrations of $\mathrm{CH}_{4}$ and $\mathrm{H}_{2}$ produced in the gut ${ }^{12}$. As seen in humans and germ-free animal models, both gases are exclusively produced by the gut microbiota ${ }^{13,14}$. A subsequent study confirmed that patients who do not produce $\mathrm{CH}_{4}$ according to BT do

${ }^{1}$ Division of General Internal Medicine, Department of Medicine, Cedars-Sinai, Los Angeles, 90048, USA. ${ }^{2}$ Medically Associated Science and Technology (MAST) program, Department of Medicine, Cedars-Sinai, Los Angeles, 90048, USA. ${ }^{3}$ Biostatistics and Bioinformatics Research Center, Cedars-Sinai, Los Angeles, 90048, USA. ${ }^{4}$ Research Informatic and Scientific Computing Core Cedars-Sinai, Los Angeles, 90048, USA. *email: ali.rezaie@cshs.org 


\begin{tabular}{|c|c|c|c|c|}
\hline \multicolumn{2}{|l|}{ Variable } & $\begin{array}{l}\text { Study Cohort } \\
(\mathrm{n}=4977)\end{array}$ & $\begin{array}{l}\text { Appendectomy } \\
(\mathrm{n}=193)\end{array}$ & $\begin{array}{l}\text { No Appendectomy } \\
(\mathrm{n}=4784)\end{array}$ \\
\hline \multicolumn{2}{|c|}{ Age (years) } & $48.0 \pm 18.4$ & $58.4 \pm 17.4$ & $47.5 \pm 18.3$ \\
\hline \multicolumn{2}{|l|}{ Male } & $1496(30.1 \%)$ & $54(28.0 \%)$ & $1442(30.1 \%)$ \\
\hline \multicolumn{2}{|c|}{$\mathrm{BMI} *\left(\mathrm{~kg} / \mathrm{m}^{2}\right)$} & $24.8 \pm 5.4$ & $25.8 \pm 5.8$ & $24.7 \pm 5.3$ \\
\hline \multirow{4}{*}{ Race** } & White & $2866(90.6 \%)$ & $169(90.4 \%)$ & $2697(90.6 \%)$ \\
\hline & Black or African American & $131(4.1 \%)$ & $8(4.3 \%)$ & $123(4.1 \%)$ \\
\hline & Asian & $84(2.7 \%)$ & $4(2.1 \%)$ & $80(2.7 \%)$ \\
\hline & Other & $82(2.6 \%)$ & $6(3.2 \%)$ & $76(2.6 \%)$ \\
\hline
\end{tabular}

Table 1. Baseline Characteristics. Patients with an appendectomy were older and more likely to be female than those without an appendectomy. BMI was higher in the group with appendectomy and race did not differ between the two groups. Values expressed as mean \pm standard deviation or number (\%). BMI = body mass index. $* \mathrm{n}=2728,181,2547$ for study cohort, appendectomy, and no appendectomy, respectively, due to missing data. $* * \mathrm{n}=3163,187,2976$ for study cohort, appendectomy, and no appendectomy, respectively, due to missing data.

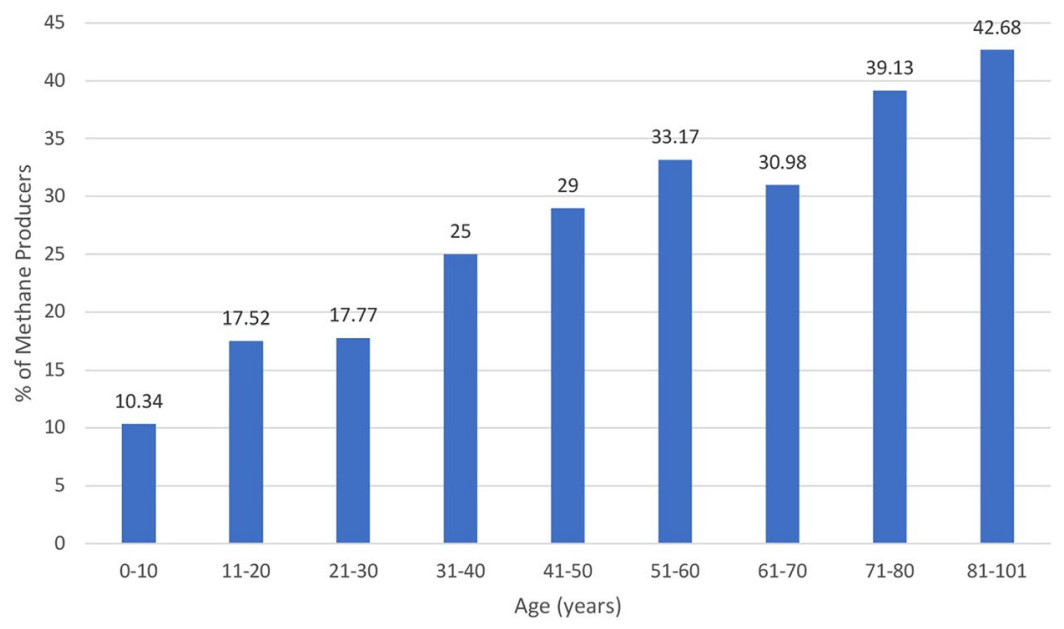

Figure 1. Depicts \% of patients who had $\mathrm{CH}_{4} \geq 1 \mathrm{ppm}$ on their breath tests with age divided in increments of 10 years. The graph shows an increase in the $\%$ of patients who produced $\mathrm{CH}_{4}$ with age. $\mathrm{CH}_{4}=$ methane. $\mathrm{n}$ in each age group starting from $0-10$ years was $58,274,698,832,962,823,736,437,157$ ).

not produce $\mathrm{CH}_{4}$ in their faeces ${ }^{15}$. Furthermore, antibiotics decrease $\mathrm{CH}_{4}$ levels, which seems to correlate with improvement in constipation associated with excessive $\mathrm{CH}_{4}$ production ${ }^{16,17}$.

Given the potential role of the appendix in the gut microbial population, we investigated the presence of $\mathrm{CH}_{4}$ in BTs in patients with and without an appendix.

\section{Results}

A total of 10,967 patients were successfully linked to electronic health records. After including only those with elevated $\mathrm{CH}_{4}$ and normal BT, 4,977 patients were included in the final cohort. Of these, 193 underwent appendectomy before BT, and 4,784 patients retained their appendix at the time of BT. The mean \pm SD age of patients at the time of BT was $48.0 \pm 18.4$ years and ranged from $2-101$ years old. There was female predominance, with 1,496 (30.1\%) males in the entire cohort. The rest of the demographics are shown in Table 1.

Effect of age on $\mathrm{CH}_{4}$ production. As previously described by our group, increased age was associated with an increased rate of excess $\mathrm{CH}_{4}$ production ${ }^{18}$. The percentage of patients with detectable $\mathrm{CH}_{4}$ increases with age, at $10.34 \%$ in those $0-10$ years, $17.52 \%$ in those $11-20$ years, $17.77 \%$ in those $21-30$ years, $25 \%$ in those $31-40$ years, $29 \%$ in those $41-50$ years, $33.17 \%$ in those $51-60,30.98 \%$ in those $61-79$ years, $39.13 \%$ in those $71-80$ years, and $42.68 \%$ in those 81-101 years (Fig. 1). For every 5-year increase in age, maximum $\mathrm{CH}_{4}$, area under the curve for $\mathrm{CH}_{4}\left(\mathrm{CH}_{4} \mathrm{AUC}\right)$, and baseline $\mathrm{CH}_{4}$ increased by 1.05 parts per million (ppm) $(p<0.0001), 5.20 \mathrm{ppm}$ $(p<0.0001)$, and $0.55 \mathrm{ppm}(p<0.0001)$, respectively. In our multivariable model fitted for age, sex, and appendectomy (Table 2), for every 5-year increase in age, the odds of having $\mathrm{CH}_{4}$ levels above the threshold increased with odds ratios (ORs) $(95 \% \mathrm{CI})$ of $1.10(1.08-1.12)(p<0.0001), 1.10(1.08-1.12)(p<0.0001), 1.10(1.08-1.12)$ $(p<0.0001)$ for $\mathrm{CH}_{4} \geq 1 \mathrm{ppm}, \mathrm{CH}_{4} \geq 3 \mathrm{ppm}$, and $\mathrm{CH}_{4} \geq 10 \mathrm{ppm}$, respectively. In the multivariable linear regression model for those with detectable $\mathrm{CH}_{4}$, a 5-year increase in age was associated with an increase in $\mathrm{CH}_{4} \mathrm{AUC}$ $(95 \% \mathrm{CI})$ of 5.27 (3.47-7.06) ppm $(p<0.0001)$ and an increase in $\mathrm{CH}_{4} \mathrm{Max}$ of $0.86(0.52-1.20) \mathrm{ppm}(p<0.0001)$. For those with excess $\mathrm{CH}_{4}$, age was associated with a significant increase in the $\mathrm{CH}_{4}$ AUC of 5.10 (3.32-6.89) 


\begin{tabular}{|l|l|l|c|}
\hline Outcome & Variables & OR $(95 \%$ CI $)$ & P-value \\
\hline \multirow{3}{*}{$\mathrm{CH}_{4} \geq 1 \mathrm{ppm}$} & Appendectomy & $0.67(0.47-0.93)$ & 0.02 \\
\cline { 2 - 4 } & Age (5 years) & $1.10(1.08-1.12)$ & $<0.0001$ \\
\cline { 2 - 4 } & Male & $1.10(0.96-1.26)$ & 0.16 \\
\hline \multirow{3}{*}{$\mathrm{CH}_{4} \geq 3 \mathrm{ppm}$} & Appendectomy & $0.65(0.46-0.92)$ & 0.01 \\
\cline { 2 - 4 } & Age (5 years) & $1.10(1.08-1.12)$ & $<0.0001$ \\
\cline { 2 - 4 } & Male & $1.10(0.96-1.26)$ & 0.15 \\
\hline \multirow{3}{*}{$\mathrm{CH}_{4} \geq 10 \mathrm{ppm}$} & Appendectomy & $0.66(0.46-0.93)$ & 0.02 \\
\cline { 2 - 4 } & Age (5 years) & $1.10(1.08-1.12)$ & $<0.0001$ \\
\cline { 2 - 4 } & Male & $1.12(0.97-1.28)$ & 0.12 \\
\hline
\end{tabular}

Table 2. Multivariable Logistic Regression Analysis $(n=4977)$. Appendectomy decreased the probability of having a detectable level or excess level of $\mathrm{CH}_{4}$. Increased age was significantly associated with $\mathrm{CH}_{4}$ production where as sex was not. $\mathrm{CH}_{4}=$ methane, ppm = parts per million.

\begin{tabular}{|l|l|l|c|}
\hline Cutoff Values & Variables & Coefficient $(\mathbf{9 5 \%}$ CI) & P-value \\
\hline \multirow{4}{*}{$\mathrm{CH}_{4} \geq 1 \mathrm{ppm}(\mathrm{n}=1404)$} & Appendectomy & $-3.50(-38.34-31.34)$ & 0.84 \\
\cline { 2 - 4 } & Age (5 years) & $5.27(3.47-7.06)$ & $<0.0001$ \\
\cline { 2 - 4 } & Male & $-30.53(-43.99--17.06)$ & $<0.0001$ \\
\hline \multirow{3}{*}{$\mathrm{CH}_{4} \geq 3 \mathrm{ppm}(\mathrm{n}=1393)$} & Appendectomy & $-0.55(-35.47-34.37)$ & 0.98 \\
\cline { 2 - 4 } & Age (5 years) & $5.10(3.32-6.89)$ & $<0.0001$ \\
\cline { 2 - 4 } & Male & $-30.91(-44.31--17.51)$ & $<0.0001$ \\
\hline & Appendectomy & $2.18(-31.44-35.79)$ & 0.9 \\
\cline { 2 - 4 } $\mathrm{CH}_{4} \geq 10 \mathrm{ppm}(\mathrm{n}=1303)$ & Age (5 years) & $5.13(3.40-6.86)$ & $<0.0001$ \\
\cline { 2 - 4 } & Male & $-35.13(-48.01--22.24)$ & $<0.0001$ \\
\hline
\end{tabular}

Table 3. Multivariable Linear Regression Analysis for $\mathrm{CH}_{4} \mathrm{AUC}$ Above Cutoff Values. Analysis of the magnitude of $\mathrm{CH}_{4} \mathrm{AUC}$ in those with detectable and excess $\mathrm{CH}_{4}$. Appendectomy, age, and sex was modeled against patients who had $\mathrm{CH}_{4} \geq 1,3$, or 10 ppm. Patients with $\mathrm{CH}_{4}$ less than the respective values were excluded. Appendectomy was not associated with an increase in $\mathrm{CH}_{4}$. Increased age and female sex were significantly associated with the magnitude of $\mathrm{CH}_{4} \mathrm{AUC} . \mathrm{CH}_{4}=$ methane, $\mathrm{ppm}=$ parts per million, $\mathrm{AUC}=$ area under the curve.

ppm $(p<0.0001)$ and $5.13(3.40-6.86)$ ppm $(p<0.0001)$ for those with $\mathrm{CH}_{4} \geq 3 \mathrm{ppm}$ and $\mathrm{CH}_{4} \geq 10$ ppm, respectively. Similarly, the $\mathrm{CH}_{4} \mathrm{Max}(95 \% \mathrm{CI})$ increased by $0.83(0.49-1.16) \mathrm{ppm}(p<0.0001)$ and $0.82(0.50-1.14) \mathrm{ppm}$ $(p<0.0001)$ in the respective groups.

Effect of appendectomy on the odds and magnitude of $\mathrm{CH}_{4}$ production. According to the multivariable analysis adjusted for age and sex, those who underwent appendectomy were less likely to be $\mathrm{CH}_{4}$ producers or have pathological levels of $\mathrm{CH}_{4}$ (Table 2). Patients who had undergone appendectomy had an OR of 0.67 $(0.47-0.93)(p=0.02)$ for detectable $\mathrm{CH}_{4} \geq 1 \mathrm{ppm}$. Sex was not a significant variable in this model, while age, as noted above, was significantly associated with increased odds of $\mathrm{CH}_{4}$ production. In the linear regression model of those who produced $\mathrm{CH}_{4} \geq 1 \mathrm{ppm}$, appendectomy was not associated with a decreased magnitude of the $\mathrm{CH}_{4}$ AUC (Table 3) or $\mathrm{CH}_{4}$ Max (Table 4). Male sex was associated with a decreased $\mathrm{CH}_{4}$ AUC and $\mathrm{CH}_{4} \mathrm{Max}$, with coefficients (SD) of $-30.53(-43.99--17.06)(p<0.0001)$ and $-4.91(-7.44--2.38)(p=0.0001)$.

Similarly, for $\mathrm{CH}_{4} \geq 3 \mathrm{ppm}$ and $\mathrm{CH}_{4} \geq 10 \mathrm{ppm}$, patients who had undergone appendectomy had decreased odds of excess $\mathrm{CH}_{4}$, with ORs of $0.65(0.46-0.92)(p=0.01)$ and $0.66(0.46-0.93)(p=0.02)$, respectively (Table 2). Sex was not a statistically significant variable in the model. Similar to our linear regression analysis of $\mathrm{CH}_{4} \geq 1 \mathrm{ppm}$, appendectomy did not seem to be associated with a change in the magnitude of excess $\mathrm{CH}_{4} \mathrm{Max}$ or the $\mathrm{CH}_{4} \mathrm{AUC}$ for those already producing $\mathrm{CH}_{4} \geq 3 \mathrm{ppm}$ and $\mathrm{CH}_{4} \geq 10 \mathrm{ppm}$ (Tables 3 and 4). Male sex was associated with a significant decrease in the $\mathrm{CH}_{4}$ AUC, with coefficients $(95 \% \mathrm{CI})$ of $-30.91(-44.31--17.51)(p<0.0001)$ for $\mathrm{CH}_{4} \geq 3$ ppm and $-35.13(-48.01--22.24)(p<0.0001)$ for $\mathrm{CH}_{4} \geq 10 \mathrm{ppm}$; the $\mathrm{CH}_{4}$ Max coefficients $(95 \% \mathrm{CI})$ were -4.98 $(-7.49--2.46)(p=0.0001)$ for $\mathrm{CH}_{4} \geq 3 \mathrm{ppm}$ and $-5.70(-8.09--3.32)(p<0.0001)$ for $\mathrm{CH}_{4} \geq 10 \mathrm{ppm}$.

In our study cohort, the area under the curve for $\mathrm{H}_{2}\left(\mathrm{H}_{2}\right.$ AUC) and baseline $\mathrm{H}_{2}$ levels did not differ between the appendectomy vs no appendectomy group, at $34.7 \pm 26.0 \mathrm{ppm}$ vs $36.6 \pm 30.3 \mathrm{ppm}(p=0.57)$ and $2.9 \pm 2.9$ ppm vs $3.1 \pm 3.7 \mathrm{ppm}(p=0.24)$, respectively.

\section{Discussion}

When adjusted for age and sex, subjects with appendectomy were less likely to produce $\mathrm{CH}_{4}$. However, among those for whom $\mathrm{CH}_{4}$ was present, the magnitude of $\mathrm{CH}_{4}$ did not differ between the two groups, despite similar $\mathrm{H}_{2}$ levels. To our knowledge, this is the first study to show an association between appendectomy and a decreased rate of excess exhaled $\mathrm{CH}_{4}$. 


\begin{tabular}{|l|l|l|c|}
\hline Cutoff Values & Variables & Coefficient $(\mathbf{9 5} \% \mathrm{CI})$ & P-value \\
\hline \multirow{3}{*}{$\mathrm{CH}_{4} \geq 1 \mathrm{ppm}(\mathrm{n}=1399)$} & Appendectomy & $0.26(-6.27-6.80)$ & 0.94 \\
\cline { 2 - 4 } & Age (5 years) & $0.86(0.52-1.20)$ & $<0.0001$ \\
\cline { 2 - 4 } & Male & $-4.91(-7.44--2.38)$ & 0.0001 \\
\hline \multirow{3}{*}{$\mathrm{CH}_{4} \geq 3$ ppm (n=1388) } & Appendectomy & $0.87(-5.67-7.41)$ & 0.79 \\
\cline { 2 - 4 } & Age (5 years) & $0.83(0.49-1.16)$ & $<0.0001$ \\
\cline { 2 - 4 } & Male & $-4.98(-7.49--2.46)$ & 0.0001 \\
\hline \multirow{3}{*}{$\mathrm{CH}_{4} \geq 10 \mathrm{ppm}(\mathrm{n}=1298)$} & Appendectomy & $1.49(-4.72-7.69)$ & 0.64 \\
\cline { 2 - 4 } & Age (5 years) & $0.82(0.50-1.14)$ & $<0.0001$ \\
\cline { 2 - 4 } & Male & $-5.70(-8.09--3.32)$ & $<0.0001$ \\
\hline
\end{tabular}

Table 4. Multivariable Linear Regression Analysis for $\mathrm{CH}_{4}$ Max Above Cutoff Values. Analysis of the magnitude of $\mathrm{CH}_{4}$ max in those with detectable and excess $\mathrm{CH}_{4}$. Appendectomy, age, and sex was modeled against patients who had $\mathrm{CH}_{4} \geq 1,3$, or $10 \mathrm{ppm}$. Patients with $\mathrm{CH}_{4}$ less than the respective values were excluded. Appendectomy was not associated with an increase in $\mathrm{CH}_{4}$. Increased age and female sex were significantly associated with the magnitude of $\mathrm{CH}_{4}$ max. $\mathrm{CH}_{4}=$ methane, $\mathrm{ppm}=$ parts per million.

It has been hypothesized that the appendix may serve as a reservoir for the gut microbiome due to its location and shape, making it relatively sheltered from microbial changes that occur in the rest of the colon ${ }^{19,20}$. During diarrhoeal illnesses, the appendix may function to repopulate the gut with its own luminal and mucosal microbiome $^{19}$. Although causality cannot be establish, the theory that the appendix may act as a microbial reservoir is supported by our finding that the number of patients with detectable or excess $\mathrm{CH}_{4}$ was decreased in the appendectomy group, but the increase in magnitude in those for whom $\mathrm{CH}_{4}$ was present did not differ between appendectomy groups. Previous studies have shown that methanogens exist in the colonic walls and stool ${ }^{21}$, and given the notable difference in the surface area and volume of the colon vs the appendix, the bulk of $\mathrm{CH}_{4}$ production likely occurs in the rest of the gut as opposed to the appendix, which may act only as a reservoir. Interestingly, diverticulosis (a form of diverticula) has been linked to an increase in methanogens, and the appendix may have a similar function ${ }^{22}$. Although of note, the appendix, unlike the diverticulum, has a muscle layer and can perform antegrade peristalsis ${ }^{23}$; hence, it can potentially act as an active reservoir for the gut microbiome. Another potential explanation for the high rates of $\mathrm{CH}_{4}$ is that a particular composition of the microbiome is associated with appendectomies, and those who do not require surgery have increased amounts of $\mathrm{CH}_{4}$.

This association between $\mathrm{CH}_{4}$ and the appendix may have clinical implications. $\mathrm{CH}_{4}$ is associated with constipation, and studies have attempted to treat this based on eliminating methanogens. Non-systemic (i.e., poorly absorbed) oral antibiotic for the treatment of methanogenic archaea in the gut appears to have a high rate of recurrence in human subjects ${ }^{24}$. This phenomenon can be potentially be explained by the theory that the appendix serves as an active reservoir of methanogenic archaea with a thick biofilm resistant to antibiotic penetrance. Future studies should consider measuring the response and recurrence rates after antibiotic treatments between those with and without an appendix to determine whether the appendix is indeed acting as a reservoir.

Additionally, a history of appendectomy has been associated with a decreased risk for developing ulcerative colitis $^{25}$ and an increased risk for Crohn's disease ${ }^{26}$. In fact, appendectomy has been proposed as a potential treatment for ulcerative colitis ${ }^{27}$. In line with our hypothesis, the importance of the role of the appendix in inflammatory bowel diseases may in part be explained by the appendix acting as a reservoir to maintain the host gut microbiome.

Another interesting observation in this study was the association between methanogens (detected by the presence of $\mathrm{CH}_{4}$ in the breath) and age. Older patients are known to have increased $\mathrm{CH}_{4}{ }^{28}$ and since the prevalence of appendectomy increases with an individual's age, this confounder warranted adjustment in this analysis. In addition, we found that age may be a significant contributor to increased $\mathrm{CH}_{4}$ levels. For every 5 -year increase in age, there was approximately a $1 \mathrm{ppm}$ increase in the $\mathrm{CH}_{4} \mathrm{Max}$, and there was a 4 -fold increase in the percentage of $\mathrm{CH}_{4}$ producers from the patient's first decade of life to the ninth decade of life (Fig. 1). This has been reported previously ${ }^{18}$. One possible explanation is that pockets in the intestine, such as the appendix and diverticula, may contribute to housing methanogens. This is evidenced by the fact that the prevalence of diverticulosis increases with age $\mathrm{e}^{29}$. Alternatively, subjects with higher levels of methanogens may have increased archaeal compositions in the gut or have longer life expectancies than those with low levels of methanogens.

This study has several strengths and weaknesses. Given the referral status of the subjects, the results of the study may not be generalizable to the general population. Due to the retrospective design, we did not have detailed information regarding patients' symptoms at the time of BT. Therefore, we were not able to correlate symptoms with the presence or absence of $\mathrm{CH}_{4}$ and appendectomy. Given that $\mathrm{CH}_{4}$ gas has been shown to decrease gut motility in humans and animal models ${ }^{30}$, it would be worthwhile to design a prospective study with symptom correlations. This new finding may hold clinical significance, as a reduction of $\mathrm{CH}_{4}$ levels has been shown to reduce constipation in humans ${ }^{17}$. There are several strengths to our study, including the large sample size and the use of the same fermentable sugar substrate (lactulose) with the same device.

In conclusion, there were decreased rates of $\mathrm{CH}_{4}$ in patients who had undergone appendectomy. Prospective studies measuring $\mathrm{CH}_{4}$ breath levels before and after appendectomy and correlating levels with symptoms, along with deep sequencing of the gut and appendix for methanogens, are warranted to investigate this new finding. 


\section{Methods}

Subjects. Consecutive lactulose BT that was performed between November 2005 and October 2013 was analysed in this study. The breath tests were performed in patients referred to a tertiary care motility clinic by other providers. The research was approved by the Cedars-Sinai Internal Review Board (IRB Protocol 00034154) and completed in accordance with institutional regulations. All data analysed for this study, including BT results, were collected during routine clinical visits, and the IRB approved the use of the data without signed consent.

Breath testing. All subjects consumed a special low-fermentable diet on the day before the test. Subjects were instructed to fast at least 12 hours prior to the test. All BT samples were collected at baseline and every subsequent 15 minutes for at least 2 hours after ingestion of $10 \mathrm{~g}$ of oral lactulose solution (Pharmaceutical Associates, Greenville, SC, USA). BT samples were analysed for $\mathrm{H}_{2}$ and $\mathrm{CH}_{4}$ after correction for carbon dioxide $\left(\mathrm{CO}_{2}\right)$ levels using gas chromatography (Quintron Instrument Company, Milwaukee, WI, USA). $\mathrm{CO}_{2}$ levels were used to adjust $\mathrm{H}_{2}$ and $\mathrm{CH}_{4}$ levels to alveolar concentrations. Subjects with a normal BT results and subjects with elevated $\mathrm{CH}_{4}$ levels $(\geq 10 \mathrm{ppm})$, as defined by the North American consensus statements, were included in the study. Subjects with elevated $\mathrm{H}_{2}$ levels $\left(>20 \mathrm{ppm}\right.$ ) and flatlines (non- $\mathrm{CH}_{4}$ and non- $\mathrm{H}_{2}$ producers) on the breath tests were excluded, as they may have indicated non-compliance with the diet, altered motility or hydrogen sulphide producers that competed for the $\mathrm{H}_{2}$ utilized by methanogens ${ }^{31}$.

Data collection. Unique patient identifiers and deterministic record linkages were used to extract demographic data (age, sex, body mass index, and race) as well as appendectomy history. The appendectomy status and clinical history of patients were further confirmed by manual chart reviews. Patients were divided into two groups according to their history of appendectomy. If patients had undergone appendectomy before BT, they were included in the appendectomy group, whereas patients who had undergone appendectomy after BT were included in the no appendectomy group. Patients who we were not able to confirm the presence or absence of the appendix with respect to their BT date were excluded from the analysis.

Statistical analysis. Numerical variables were summarized by means and standard deviations (SDs). Means of numerical variables with approximately normal distributions were compared across groups by independent samples t-tests. Categorical variables were summarized by frequencies and percentages, and group comparisons were made using chi-square tests. We defined the $\mathrm{CH}_{4} \mathrm{Max}$ as the highest $\mathrm{CH}_{4}$ measured in one breath over the course of BT for every patient. The $\mathrm{H}_{2} \mathrm{AUC}$ and $\mathrm{CH}_{4}$ AUC were calculated by the summation of $\mathrm{H}_{2}$ and $\mathrm{CH}_{4}$ levels at 90 minutes, respectively. Baseline $\mathrm{CH}_{4}$ and $\mathrm{H}_{2}$ were measured in the first breath prior to the administration of the lactulose. $\mathrm{CH}_{4}$ levels were markedly non-normal, with a high proportion of zero and small values, therefore they could not be fitted with standard linear regression. Thus, we assessed factors associated with $\mathrm{CH}_{4}$ levels in a two-step modelling procedure. First, we used multivariable logistic regression to model being at or above specific thresholds: $\geq 1 \mathrm{ppm}$ (detectable) and the potentially clinically important thresholds of $\geq 3 \mathrm{ppm}$ and $\geq 10 \mathrm{ppm}$ (excess) ${ }^{12}$. In the second step, for those subjects at or above each specific threshold, we used multivariable linear regression to model the $\mathrm{CH}_{4}$ Max and $\mathrm{CH}_{4}$ AUC. To approximate a normal distribution, we excluded 5 outliers with the highest $\mathrm{CH}_{4}$ Max values in our analysis (this did not alter the significance of our study). Univariable comparisons of $\mathrm{CH}_{4}$ and $\mathrm{H}_{2}$ variables were made using Wilcoxon rank sum tests because of their highly skewed distributions. All analyses were performed using SAS version 9.4 (SAS Institute, Cary, NC, USA). We used a standard two-tailed alpha of 0.05 to determine significance.

\section{Data availability}

The datasets generated and analysed in the current study are available from the corresponding author upon reasonable request.

Received: 30 April 2019; Accepted: 23 December 2019;

Published online: 21 January 2020

\section{References}

1. Kawanishi, H. Immunocompetence of normal human appendiceal lymphoid cells: in vitro studies. Immunology 60, 19-28 (1987).

2. Dasso, J. F., Obiakor, H., Bach, H., Anderson, A. O. \& Mage, R. G. A morphological and immunohistological study of the human and rabbit appendix for comparison with the avian bursa. Dev. Comp. Immunol. 24, 797-814 (2000).

3. Palestrant, D. et al. Microbial biofilms in the gut: visualization by electron microscopy and by acridine orange staining. Ultrastruct. Pathol. 28, 23-27 (2004).

4. Guinane, C. M. et al. Microbial composition of human appendices from patients following appendectomy. MBio 4, e00366-12, https://doi.org/10.1128/mBio.00366-12 (2013).

5. Jackson, H. T. et al. Culture-independent evaluation of the appendix and rectum microbiomes in children with and without appendicitis. PLoS One 9, e95414, https://doi.org/10.1371/journal.pone.0095414 (2014).

6. Gaci, N., Borrel, G., Tottey, W., O’Toole, P. W. \& Brugère, J. F. Archaea and the human gut: new beginning of an old story. World J. Gastroenterol. 20, 16062-16078 (2014).

7. Lurie-Weinberger, M. N. \& Gophna, U. Archaea in and on the Human Body: Health Implications and Future Directions. PLoS Pathog. 11, e1004833, https://doi.org/10.1371/journal.ppat.1004833 (2015).

8. Garcia, J. L., Patel, B. K. \& Ollivier, B. Taxonomic, phylogenetic, and ecological diversity of methanogenic Archaea. Anaerobe 6, 205-226 (2000).

9. Miller, T. L. \& Wolin, M. J. Methanosphaera stadtmaniae gen. nov., sp. nov.: a species that forms methane by reducing methanol with hydrogen. Arch. Microbiol. 141, 116-122 (1985).

10. Miller, T. L., Wolin, M. J., Conway de Macario, E. \& Macario, A. J. Isolation of Methanobrevibacter smithii from human feces. Appl. Environ. Microbiol. 43, 227-232 (1982).

11. Chaudhary, P. P., Conway, P. L. \& Schlundt, J. Methanogens in humans: potentially beneficial or harmful for health. Appl. Microbiol. Biotechnol. 102, 3095-3104 (2018). 
12. Rezaie, A. et al. Hydrogen and Methane-Based Breath Testing in Gastrointestinal Disorders: The North American Consensus. Am. J Gastroenterol. 112, 775-784 (2017).

13. Levitt, M. D. Volume and composition of human intestinal gas determined by means of an intestinal washout technic. N. Engl. J. Med. 284, 1394-1398 (1971).

14. Bond, J. H., Engel, R. R. \& Levitt, M. D. Factors influencing pulmonary methane excretion in man. An indirect method of studying the in situ metabolism of the methane-producing colonic bacteria. J. Exp. Med. 133, 572-588 (1971).

15. Christl, S. U., Murgatroyd, P. R., Gibson, G. R. \& Cummings, J. H. Production, metabolism, and excretion of hydrogen in the large intestine. Gastroenterology 102, 1269-1277 (1992).

16. Low, K. et al. A combination of rifaximin and neomycin is most effective in treating irritable bowel syndrome patients with methane on lactulose breath test. J. Clin. Gastroenterol. 44, 547-550 (2010).

17. Pimentel, M., Chatterjee, S., Chow, E. J., Park, S. \& Kong, Y. Neomycin improves constipation-predominant irritable bowel syndrome in a fashion that is dependent on the presence of methane gas: subanalysis of a double-blind randomized controlled study. Dig. Dis. Sci. 51, 1297-1301 (2006).

18. Chang, B. W., Pimentel, M., Chang, C., Chua, K. S. \& Rezaie, A. Prevalence of Excessive Intestinal Methane Production and Its Variability With Age and Gender: A Large-Scale Database Analysis [Abstract]. Gastroenterology 148, S-729-S-730 (2015).

19. Kooij, I. A., Sahami, S., Meijer, S. L., Buskens, C. J. \& Te Velde, A. A. The immunology of the vermiform appendix: a review of the literature. Clin. Exp. Immunol. 186, 1-9 (2016).

20. Girard-Madoux, M. J. H. et al. The immunological functions of the Appendix: An example of redundancy? Semin. Immunol. 36, 31-44 (2018)

21. Eckburg, P. B. et al. Diversity of the human intestinal microbial flora. Science 308, 1635-1638 (2005).

22. Weaver, G. A., Krause, J. A., Miller, T. L. \& Wolin, M. J. Incidence of methanogenic bacteria in a sigmoidoscopy population: an association of methanogenic bacteria and diverticulosis. Gut 27, 698-704 (1986).

23. Singh, P. B. et al. Effect of Agonist and Antagonist on the In Vitro Contractility of Inflamed Vermiform Appendix. J. Clin. Diagn. Res. 11, CC25-CC30 (2017)

24. Pimentel, M. et al. Antibiotic treatment of constipation-predominant irritable bowel syndrome. Dig. Dis. Sci. 59, 1278-1285 (2014).

25. Koutroubakis, I. E. \& Vlachonikolis, I. G. Appendectomy and the development of ulcerative colitis: results of a metaanalysis of published case-control studies. Am. J. Gastroenterol. 95, 171-176 (2000).

26. Andersson, R. E., Olaison, G., Tysk, C. \& Ekbom, A. Appendectomy is followed by increased risk of Crohn's disease. Gastroenterology 124, 40-46 (2003).

27. Gardenbroek, T. J. et al. The ACCURE-trial: the effect of appendectomy on the clinical course of ulcerative colitis, a randomised international multicenter trial (NTR2883) and the ACCURE-UK trial: a randomised external pilot trial (ISRCTN56523019). BMC Surg. 15, 30 (2015).

28. Polag, D., Leiß, O. \& Keppler, F. Age dependent breath methane in the German population. Sci. Total Environ. 481, 582-587 (2014).

29. Peery, A. F. et al. A high-fiber diet does not protect against asymptomatic diverticulosis. Gastroenterology 142, 266-272.e1 (2012).

30. Pimentel, M. et al. Methane, a gas produced by enteric bacteria, slows intestinal transit and augments small intestinal contractile activity. Am. J. Physiol. Gastrointest. Liver Physiol. 290, G1089-1095 (2006).

31. Linden, D. R. Hydrogen sulfide signaling in the gastrointestinal tract. Antioxid. Redox. Signal 20, 818-830 (2014).

\section{Author contributions}

W.T.- study design; acquisition of data; analysis and interpretation of data; drafting of the manuscript; critical revision of the manuscript for important intellectual content; statistical analysis; administrative, technical, or material support. S.J.- acquisition of data; analysis and interpretation of data; drafting of the manuscript; critical revision of the manuscript for important intellectual content; statistical analysis; administrative, technical, or material support. T.S.- acquisition of data; analysis and interpretation of data; drafting of the manuscript; critical revision of the manuscript for important intellectual content; statistical analysis; administrative, technical, or material support. J.M.- study design; analysis and interpretation of data; drafting of the manuscript; critical revision of the manuscript for important intellectual content; statistical analysis; administrative, technical, or material support. G.L.- study design; acquisition of data; analysis and interpretation of data; drafting of the manuscript; critical revision of the manuscript for important intellectual content; statistical analysis; administrative, technical, or material support. A.F.- study design; acquisition of data; analysis and interpretation of data; drafting of the manuscript; critical revision of the manuscript for important intellectual content; statistical analysis; administrative, technical, or material support. M.P.- study concept and design; acquisition of data; analysis and interpretation of data; drafting of the manuscript; critical revision of the manuscript for important intellectual content; statistical analysis; administrative, technical, or material support; study supervision. R.M.study concept and design; acquisition of data; analysis and interpretation of data; drafting of the manuscript; critical revision of the manuscript for important intellectual content; statistical analysis; administrative, technical, or material support; study supervision. N.P.- study concept and design; acquisition of data; analysis and interpretation of data; drafting of the manuscript; critical revision of the manuscript for important intellectual content; statistical analysis; administrative, technical, or material support; study supervision. A.R.- study concept and design; acquisition of data; analysis and interpretation of data; drafting of the manuscript; critical revision of the manuscript for important intellectual content; statistical analysis; administrative, technical, or material support; study supervision.

\section{Competing interests}

The authors declare no competing interests.

\section{Additional information}

Correspondence and requests for materials should be addressed to A.R.

Reprints and permissions information is available at www.nature.com/reprints.

Publisher's note Springer Nature remains neutral with regard to jurisdictional claims in published maps and institutional affiliations. 
(c) (i) Open Access This article is licensed under a Creative Commons Attribution 4.0 International License, which permits use, sharing, adaptation, distribution and reproduction in any medium or format, as long as you give appropriate credit to the original author(s) and the source, provide a link to the Creative Commons license, and indicate if changes were made. The images or other third party material in this article are included in the article's Creative Commons license, unless indicated otherwise in a credit line to the material. If material is not included in the article's Creative Commons license and your intended use is not permitted by statutory regulation or exceeds the permitted use, you will need to obtain permission directly from the copyright holder. To view a copy of this license, visit http://creativecommons.org/licenses/by/4.0/.

(C) The Author(s) 2020 